\title{
A SABOTAGEM DA CIÊNCIA BRASILEIRA ENTRE 2016 E 2017
}

\author{
THE SABOTAGE OF BRAZILIAN SCIENCE: 2016 AND 2017
}

\section{EL SABOTAJE DE LA CIENCIA BRASILEÑA: 2016 Y 2017}

DOI: http://dx.doi.org/10.9771/gmed.v11i3.34758

\section{Roberto Barbosa ${ }^{1}$}

Resumo: Apresentar e compreender as práticas governamentais que afetaram negativamente a ciência brasileira entre os anos de 2016 e 2017 é o objetivo desse trabalho. A substituição do governo Dilma pelo governo Temer trouxe uma série de consequências para a Ciência brasileira. A sanção da PEC 55, a privatização da Petrobras e a extinção da lei do Pré-sal são algumas das ações do governo brasileiro que causaram uma mudança drástica nas políticas de financiamentos de pesquisa. Para analisar essa realidade nos subsidiamos no materialismo histórico dialético a partir de duas categorias a totalidade e a violência que explicitam a natureza do fenômeno estudado.

Palavras-chave: Ciência brasileira; universidades públicas; política científica; materialismo dialético.

Abstract: Present and understanding the government practices which negatively affected the Brazilian Science between 2016 and 2017, is main goal of this paper. The Dilma's government replacement by Temer brought several consequences for Brazilian Science. The Pec 55 sanction, the Petrobras privatization, the Pré-sal law extinction are some of the actions of the Brazilian government that provoked serious changes on the financing policies of research. To analyze this reality, we grounded in dialectical historical materialism from two categories the totality and the violence that explain the nature of the studied phenomenon.

Keywords: Brazilian science; public universities; scientific policies; dialectical materialism.

Resumen: Presentar y comprender las prácticas gubernamentales que afectaron negativamente a la ciencia brasileña entre los años 2016 y 2017 es objetivo de ese trabajo. La sustitución del gobierno Dilma por el gobierno Temer trajo una serie de consecuencias para la Ciencia brasileña. La sanción de la PEC 55, la privatización de Petrobras y la extinción de la ley del Pre-sal son algunas de las acciones del gobierno brasileño que causaron un cambio drástico en las políticas de financiación de investigación. Para analizar esta realidad subvencionamos en el materialismo histórico dialéctico de dos categorías la totalidad y la violencia que explican la naturaleza del fenómeno estudiado.

Palabras clave: Ciencia brasileña; universidades; política científica; materialismo dialéctico.

\section{Introdução}

\begin{abstract}
A história nos mostra que as instituições de Ensino e Pesquisa são tradicionalmente aquelas que mais sofrem nos períodos de crise econômica. Segundo a Academia de Ciências da América Latina, que se reuniu há cerca de um ano, "o sistema científico e tecnológico está sendo considerado apenas como mais um setor do aparelho burocrático do Estado, a ser reduzido com vistas ao equilíbrio fiscal ...". Ela atribui ainda a desintegração do sistema científico da América Latina ao pensar "a ciência e a tecnologia [como] atividades que podem ser postergadas até que sobrevenham épocas melhores (CARUSO, 1991, p.1).
\end{abstract}

Essas são as palavras do físico brasileiro Francisco Caruso no ano de 1991 durante o governo de Fernando Collor de Mello período no qual as universidades estavam sucateadas e ameaçadas pela iniciativa privada, um fato que reforça que no Brasil existiram outros momentos na história em que as instituições de pesquisa e universidades sofreram cortes e retrocessos. A citação acima sobretudo parece refletir um pouco 
do momento que se vive hoje. O discurso governamental naquele período em relação a escassez de recursos é o mesmo que se adotava em 2018 e que se adota em 2019, porém diferentemente de 1991 em 2016 o Brasil posicionava-se como a nona potência econômica do mundo, em 2012 chegou a estar na quinta posição e portanto não se pode dizer que havia falta de recursos. E é neste contexto que tentamos elencar e analisar as diversas ações governamentais a partir de 2016 para cortar investimentos e ameaçar centenas de atividades de pesquisas em institutos e universidades públicas brasileiras.

Os cortes somaram 7,5 bilhões de reais apenas entre os anos 2016 e 2017. Em agosto de 2017 a revista nature publicou um artigo no qual destacou a redução drástica das verbas destinadas a Ciência no Brasil e na Argentina durante este período, segundo Anna Petherick (2017), a austeridade de ambos os governos ameaça as pesquisas e os pesquisadores que têm destaque científico dentro e fora do país. Em relação ao Rio de Janeiro, Petherick afirma que a agência de fomento à pesquisa do estado, a FAPERJ, está falida, mas ainda aceita pedidos de novos projetos.

Neste contexto e com o objetivo de compreendermos tais ações propõe-se realizar uma análise à luz do materialismo histórico dialético sob duas dimensões ou categorias, a totalidade e a violência com as quais espera-se responder as seguintes questões: Quais os propósitos ocultos por trás dessas práticas? A quem interessa o atrofiamento da C\&T no Brasil? A quem interessa que o Brasil permaneça científica e tecnologicamente dependente? tais questões além de explicitar nossas hipóteses visa situar a pesquisa e a ciência brasileira em um cenário mais amplo, no qual a política é a regularidade, que provoca a desordem institucional acadêmica, educacional e de pesquisa nos institutos e universidades brasileiras.

Para apresentar esta análise dividimos o texto em duas partes: a primeira, a História e a segunda, a análise da História e por fim as considerações finais.

\section{A História - ações do governo Temer para sabotar a ciência brasileira}

Neste tópico apresentamos as inúmeras ações governamentais ocorridas durante o governo de Michel Temer para sabotar a ciência brasileira, os diversos fatos que foram ampla e abertamente divulgados pela mídia nacional e internacional.

\section{Fim do Ministério da Ciência Tecnologia e Inovação e criação do MCTIC}

Em 12 de maio de 2016 por medida provisória o presidente interino Michel Temer Medida, convertida na Lei n 13.341, de 29 de setembro de 2016, extinguiu o Ministério das Comunicações e transformou o Ministério da Ciência, Tecnologia e Inovação em Ministério da Ciência, Tecnologia, Inovações e Comunicações (MCTIC), com argumento de expansão do leque de contribuições do órgão na entrega de serviços públicos relevantes para o desenvolvimento do país. Antes dessa fusão a pasta do Ministério da Ciência Tecnologia e Inovação tinha como competência os seguintes assuntos:

- $\quad$ Política nacional de pesquisa científica, tecnológica e inovação;

- $\quad$ Planejamento, coordenação, supervisão e controle das atividades da ciência e tecnologia; 
- Política de desenvolvimento de informática e automação;

- Política nacional de biossegurança;

- Política espacial;

- Política nuclear;

- $\quad$ Controle da exportação de bens e serviços sensíveis.

Depois acresceu-se as competências do Ministério da Comunicação:

- Política nacional de telecomunicações;

- $\quad$ Política nacional de radiodifusão;

- $\quad$ Serviços postais, telecomunicações e radiodifusão;

- Política nacional de inclusão digital.

Além da responsabilidade pela Articulação com os Governos dos Estados, do Distrito Federal e dos Municípios, com a sociedade civil e com órgãos do Governo federal para estabelecimento de diretrizes para as políticas nacionais de ciência, tecnologia e inovação, reforça a MP.

Embora diversas entidades científicas tenham se manifestado contra esta fusão, o governo manteve sua posição. As consequências dessa decisão não são todas conhecidas, mas o que se pode afirmar é que o investimento em Ciência e tecnologia foi reduzido pela metade.

\section{A PEC 95/55 ou 241 de 2016}

No dia 13 de dezembro de 2016, 4 meses aproximadamente após o afastamento de presidenta Dilma Rousseff, o senado federal pela segunda vez aprova a Proposta de Emenda Constitucional $n^{\circ} 55$ de iniciativa da Presidência da República. Na íntegra a PEC 55:

Institui o Novo Regime Fiscal no âmbito dos Orçamentos Fiscal e da Seguridade Social da União, que vigorará por 20 exercícios financeiros, existindo limites individualizados para as despesas primárias de cada um dos três Poderes, do Ministério Público da União e da Defensoria Pública da União; sendo que cada um dos limites equivalerá: I - para o exercício de 2017, à despesa primária paga no exercício de 2016, incluídos os restos a pagar pagos e demais operações que afetam o resultado primário, corrigida em 7,2\% e II - para os exercícios posteriores, ao valor do limite referente ao exercício imediatamente anterior, corrigido pela variação do Índice Nacional de Preços ao Consumidor Amplo IPCA. Determina que não se incluem na base de cálculo e nos limites estabelecidos: I transferências constitucionais; II - créditos extraordinários III - despesas não recorrentes da Justiça Eleitoral com a realização de eleições; e IV - despesas com aumento de capital de empresas estatais não dependentes"2

Mesmo a após a "vitória" do "Não" (345.656) em contraposição ao "Sim" (23.766) via consulta pública pelo site do senado federal e também sob os apelos de entidades científicas como a SBF (Sociedade Brasileira de Física) a PEC 55 foi aprovada e sancionada em 16 de dezembro de 2016 pelo então presidente Michel Temer. Antes dessa data no dia 25 de novembro a Sociedade Brasileira de Física emitiu uma carta aberta em que manifestava preocupação com as possíveis consequências a ciência e as demais áreas públicas da educação e da saúde brasileira. Segue-se um trecho:

A aprovação da PEC 55 (antiga PEC 241), em trâmite no Senado Federal, terá um efeito desastroso para o desenvolvimento científico e tecnológico e para a educação no Brasil. Se aprovada ela limitará à taxa da inflação, pelos próximos 20 (vinte) anos, o crescimento dos gastos públicos. No caso da ciência e tecnologia, o orçamento do MCTIC ficará 
congelado no valor mais baixo dos últimos 15 anos, e que já é hoje claramente insuficiente. Tal emenda, que altera profundamente disposições constitucionais, está sendo levada à frente sem ter sido debatida com a sociedade ou submetida ao crivo democrático da população brasileira. Ao congelar por duas décadas os investimentos públicos para ciência e tecnologia, educação, saúde e outras áreas sociais, a PEC 55 coloca em sério risco o futuro da educação e da pesquisa nas universidades e instituições públicas de pesquisa, bem como afeta direitos sociais de grande parte da população brasileira.

E de fato, muito antes dos 20 anos os cortes foram implementados, somente entre o fim do ano 2016 e início de 2017 o corte foi de aproximadamente 7,5 bilhões de reais, ou seja, de 75\% se comparado ao valor máximo já investido em Ciência no Brasil que chegou a 10 Bilhões de reais em 2010. Isso resultou numa série de consequências como os cortes nas Bolsas de iniciação científica e de Pós-graduação e também na redução de 44\% das verbas destinadas as Universidades Federais bem como ao CNPq.

\section{Extinção da Lei do Pré-Sal (Lei 12.351, de 22 de dezembro de 2010)}

Em 29 de novembro de 2016 o presidente interino Michel Temer sancionou a lei 4567/16 (lei ordinária 13365/2016) de autoria do senador José Serra que retira a exclusividade da estatal brasileira Petrobras da exploração do Pré-sal e a cota mínima de 30\% de participação em todos os campos, ou seja, revoga a Lei do Pré-sal sancionado pelo então presidente Luiz Inácio Lula da Silva em dezembro de 2010; que entre outras coisas destinava 50\% dos seus royalties para um Fundo Social (FS). O objetivo desse Fundo Social era constituir uma fonte de recursos para o desenvolvimento social e regional, na forma de programas e projetos nas áreas de combate à pobreza e de desenvolvimento: I - da educação; II - da cultura; III - do esporte; IV - da saúde pública; V - da ciência e tecnologia; VI - do meio ambiente; e VII - de mitigação e adaptação às mudanças climáticas (Art. 47, p. 16).

Com isso, a constituição do Fundo Social ficou comprometido já que petroleiras internacionais passam também a extrair o petróleo do Pré-Sal sem a participação da Petrobras. Segundo Steve Austin (2017), técnico de operação da Replan e diretor do Sindipetro Unificado do Estado de São Paulo, a exclusividade fazia parte de uma estratégia energética de longo prazo, em que a curva de produção acompanharia a demanda nacional para evitar uma exploração predatória. Essa estratégia era alinhada a um projeto de desenvolvimento socioeconômico, com base em dois pilares, a política de conteúdo nacional para desenvolvimento da indústria de máquinas e equipamentos e a criação do fundo social, visando fomentar as áreas de saúde e educação.

\section{A política de desinvestimentos e privatização da Petrobras e de outras Estatais ameaçam}

\section{Universidades e Centros de pesquisa nacionais}

A Petrobras assim como a Embraer e a Eletrobrás são estatais brasileiras ou empresas de economia mista que financiam projetos sociais bem como pesquisas científicas e tecnológicas nacionais. A privatização ou venda de qualquer uma dessas instituições, reduz o investimento nessas áreas. Após o golpe de 2016 contra a presidenta Dilma, diversos campos de petróleos foram vendidos, e a Petrobras reduziu em um Bilhão de reais a estimativa de investimentos em pesquisa para o ano de 2017. Para se ter uma noção do 
prejuízo a Ciência brasileira dessas ações José Mauro de Moraes (2013) destaca o papel da estatal nas pesquisas em universidades brasileiras. Segundo ele as pesquisas e o desenvolvimento tecnológico em universidades e centros de pesquisa na área de extração de petróleo em águas profundas no Brasil evoluíram a partir das necessidades da Petrobras.

Nós identificamos que cerca de oito mil pesquisadores participam atualmente das redes de pesquisa da Petrobras que estão incorporadas aos estudos desenvolvidos nas universidades em função de solicitações e de pesquisas da companhia". Em vinte anos, os acordos entre Petrobras e universidades originaram cerca de quatro mil projetos de pesquisas que foram distribuídos entre 100 instituições de ensino brasileiras das quais a mais importante é a Universidade Federal do Rio de Janeiro (UFRJ), responsável por mil pesquisas no período de 1992 a 2009. E o custo desses contratos para a Petrobras, segundo Morais, totalizaram 3 bilhões de reais em valores correntes. Desses investimentos resultou a série de recordes de exploração de petróleo em águas profundas batidos pela companhia de 1979 até 2012. "Nesse período, a Petrobras avança desde 189 metros abaixo do nível da lâmina d'água, no campo de Enchova, onde estabelece seu primeiro recorde mundial, até os 2.500 metros alcançados na instalação de uma unidade flutuante de produção em Cascade, no Golfo do México, em 2012 (MORAES, 2013, p.66).

Uma realidade que é demonstrada no quadro a seguir, no qual expõe-se os valores em milhões dos contratos com universidades, centros e institutos de pesquisa entre os anos de 1992 e 2009.

Quadro 1 - Universidades contratadas pela Petrobras

CENPES - Universidades e instituições de pesquisas contratadas (1992-2009)

\begin{tabular}{|c|c|c|}
\hline Áreas & $\begin{array}{c}\mathrm{N}^{\circ} \text { de } \\
\text { contratos }\end{array}$ & $\begin{array}{c}\text { Valor total } \\
\text { dos contratos }\end{array}$ \\
\hline UFRJ - Universidade Federal do Rio de Janeiro & 994 & 741,1 \\
\hline PUC-RIO - Pontifícia Universidade Católica do Rio de Janeiro & 477 & 417,3 \\
\hline UNICAMP - Universidade Estadual de Campinas & 190 & 122,4 \\
\hline USP - Universidade de São Paulo & 154 & 131,0 \\
\hline UFRN - Universidade Federal do Rio Grande do Norte & 151 & 108,0 \\
\hline IPT - Instituto de Pesquisas Tecnológicas do Estado de São Paulo S.A. & 134 & 93,0 \\
\hline UFRGS - Universidade Federal do Rio Grande do Sul & 112 & 79,7 \\
\hline UFSC - Universidade Federal de Santa Catarina & 95 & 80,0 \\
\hline UFF - Universidade Federal Fluminense & 88 & 74,7 \\
\hline UFBA - Universidade Federal da Bahia & 77 & 62,0 \\
\hline COPPETEC - Fundação Coordenação de Projetos, Pesquisas e Estudos Tecnológicos & 76 & 27,1 \\
\hline UFPE - Universidade Federal de Pernambuco & 59 & 51,0 \\
\hline INT - Instituto Nacional de Tecnologia & 54 & 52,2 \\
\hline UFC - Universidade Federal do Ceará & 54 & 29,2 \\
\hline UERJ - Universidade do Estado do Rio de Janeiro & 46 & 39,4 \\
\hline UFPR - Universidade Federal do Paraná & 40 & 22,5 \\
\hline UENF - Universidade Estadual Norte Fluminense Darcy Ribeiro & 37 & 40,5 \\
\hline BIORIO - Fundação Bio-Rio & 36 & 13,5 \\
\hline UFS - Universidade Federal de Sergipe & 34 & 53,4 \\
\hline CEPEL - Centro de Pesquisas de Energia Elétrica & 32 & 4,6 \\
\hline UNIFACS - Universidade Salvador & 31 & 19,2 \\
\hline FAURGS - Fundação de Apoio da Universidade Federal do Rio Grande do Sul & 30 & 11,4 \\
\hline UFES - Universidade Federal do Espírito Santo & 30 & 63,1 \\
\hline UFU - Universidade Federal de Uberlândia & 30 & 16,0 \\
\hline Outras universidades e instituições de pesquisa & 886 & 820,2 \\
\hline TOTAL & 3.947 & $3.172,6$ \\
\hline
\end{tabular}


Fonte: Dados CENPE, IPA, José Mauro de Moraes (2006).

Como se nota a partir do quadro 1 , o investimento em pesquisa e desenvolvimento tecnológico pela Petrobras envolveu mais de 3 bilhões de reais no período destacado, o que a levou ao reconhecimento internacional pelas inovações na exploração de petróleo no qual recebeu em 1992, e novamente em 2001, o prêmio Distinguished Achievement Award, da Offshore Technology Conference (OTC), de Houston, Texas, o maior prêmio internacional na área petrolífera. Diversas inovações tecnológicas da Companhia foram adotadas na produção de petróleo em outras regiões petrolíferas do mundo.

\title{
Fim do Ciência sem Fronteiras
}

Em abril de 2016, o Ministério da Educação (MEC) anunciou o fim do Programa Ciência sem Fronteiras (CsF) que concedeu entre 2011 e 2016 quase 104 mil bolsas, dessas 78,9 mil para estudantes de graduação. Neste Período foram investidos aproximadamente 13 bilhões de reais. Segundo o site do Programa,

\begin{abstract}
Ciência sem Fronteiras é um programa que busca promover a consolidação, expansão e internacionalização da ciência e tecnologia, da inovação e da competitividade brasileira por meio do intercâmbio e da mobilidade internacional. A iniciativa é fruto de esforço conjunto dos Ministérios da Ciência, Tecnologia e Inovação (MCTI) e do Ministério da Educação (MEC), por meio de suas respectivas instituições de fomento - CNPq e Capes -, e Secretarias de Ensino Superior e de Ensino Tecnológico do MEC. [...] Além disso, busca atrair pesquisadores do exterior que queiram se fixar no Brasil ou estabelecer parcerias com os pesquisadores brasileiros nas áreas prioritárias definidas no Programa, bem como criar oportunidade para que pesquisadores de empresas recebam treinamento especializado no exterior (MEC, 2016).
\end{abstract}

Vinculado à Capes e ao CNPQ o programa adotava parcerias com as universidades brasileiras que eram responsáveis pela seleção dos bolsistas.

Elogiado pelos estudantes e criticado por alguns membros da comunidade científica nacional, tal qual a presidente da SBPC (Sociedade Brasileira para o Progresso da Ciência) no período, Helena Nader afirmou que "internacionalizar a ciência requer uma estratégia elaborada e de longo prazo e em nenhum país do mundo se baseia só em mandar alunos de graduação para o exterior", porém podia-se perguntar se a CAPES, o CNPQ e os gestores das universidades não tinham discernimento do processo em que estavam envolvidas? Fizeram todo esse investimento sem um planejamento? Enfim, o programa não foi reavaliado, nem reduzido, foi extinto.

\section{Desmonte da UERJ e a ameaça pelo governo Federal de privatização}

No dia 10 de janeiro de 2017, a revista espaço e economia publicou uma nota do reitor Ruy Garcia Marques e da vice-reitora Maria Georgina Muniz Washington que após mencionarem a história e a importância da universidade para o Rio de Janeiro, desabafaram;

A Uerj está sendo sucateada, numa absoluta falta de visão estratégica por parte dos governantes do nosso Estado, a quem incumbe o financiamento de uma universidade pública e inclusiva como a nossa. Desprezar o ensino superior, a pós-graduação e a pesquisa é apostar na miséria, na violência e num futuro sem perspectivas 
positivas. Forçar o fechamento da Uerj é não pensar no futuro de nosso estado e de nosso país. A Uerj e o Estado são perenes, os governantes não (EDITORIAl, 2017).

Inclusive o juiz e ministro do supremo tribunal federal Luiz Roberto Barroso em artigo publicado no jornal O Globo no dia 15 do mesmo mês, defendeu um modelo de financiamento privado para as Universidades Públicas nos moldes norte-americano. Uma ideia ou sugestão também defendida no dia $1^{\circ}$ de setembro de 2017 pelo ministro da Fazenda Henrique Meirelles que apontou como "solução" da crise do estado do Rio a demissão de servidores estaduais, extinção de mais empresas públicas e a "revisão da oferta de ensino superior" que sugere a privatização das universidades estaduais.

Nesse período funcionários e docentes já estavam a mais de três meses sem receber salários e projetos de pesquisa estavam suspensos em razão dos problemas de repasses do governo que duravam a mais de um ano.

\section{Prisão de reitores e professores universitários - O caso UFSC-Prisão e morte do Reitor Luiz Carlos Cancellier de Olivo}

No dia 14 de setembro de 2017 o reitor da UFSC (Universidade Federal de Santa Catarina), professor Luiz Carlos Cancellier de Olivo, e seis outras pessoas ligadas à instituição foram detidas por agentes da polícia federal. Acusados de pertencer a uma "suposta" organização criminosa que "supostamente" desviava recursos do programa de Educação a Distância (EaD) em um período que o mesmo não era Reitor. Segundo o jornal Elpaís (TORRES, 2017)

Cancellier foi interrogado por sete horas. Negou qualquer tentativa de barrar as investigações. Também expôs que era um defensor do programa UAB, que considerava uma maneira concreta de democratizar a educação. E passou mais 30 horas na Penitenciária da Agronômica, em Florianópolis. Sua prisão foi decretada por ordem da juíza federal Janaína Cassol Machado. Ele e os outros seis presos deveriam passar mais quatro dias na prisão, mas no dia seguinte, acabaram soltos pela juíza Marjôrie Cristina Freiberger, que substituía Machado, ausente por motivos médicos.

Em outra nota o jornal El País (2017), noticiou:

em 14 de setembro último, Cancellier foi preso, despido, algemado. Virou símbolo de um esquema de corrupção milionário dentro da universidade, um escândalo noticiado pelos maiores jornais do Brasil. Sua foto com uniforme laranja de presidiário circulou pelas redes sociais. Não demoraram os ataques de ódio (TORRES, 2017).

No dia 28 de setembro de 2017 o jornal O Globo publicou um artigo do reitor Cancellier com o título "Reitor Exilado" em que ele diz:

A humilhação e o vexame a que fomos submetidos - eu e outros colegas da Universidade Federal de Santa Catarina (UFSC) — há uma semana não tem precedentes na história da instituição. No mesmo período em que fomos presos, levados ao complexo penitenciário, despidos de nossas vestes e encarcerados, paradoxalmente a universidade que comando desde maio de 2016 foi reconhecida como a sexta melhor instituição federal de ensino superior brasileira; avaliada com vários cursos de excelência em pósgraduação pela Capes e homenageada pela Assembleia Legislativa de Santa Catarina. Nos últimos dias tivemos nossas vidas devassadas e nossa honra associada a uma "quadrilha", acusada de desviar R\$ 80 milhões. E impedidos, mesmo após libertados, de entrar na universidade. (CONCELIER, 2017). 
Quatro dias após essa publicação, uma nota emitida pela UFSC dizia: A Universidade Federal de Santa Catarina (UFSC) informa, com pesar, o falecimento do reitor Luiz Carlos Cancellier de Olivo, na manhã desta segunda-feira, 2 de outubro.

O reitor afastado da Universidade Federal de Santa Catarina (UFSC), Luiz Carlos Cancellier, morreu na manhã desta segunda-feira, no Shopping Beira-Mar, em Florianópolis. O reitor assumiu a universidade em 2016, mas foi afastado das suas funções por uma decisão judicial na Operação Ouvidos Moucos que investigava irregularidades de 2006. Cancellier, mesmo tendo assumido o cargo 10 anos depois, sempre esteve à disposição para esclarecimentos das irregularidades de gestões anteriores (UFSC, 2017).

No mesmo dia, a Andifes - A Associação Nacional dos Dirigentes das Instituições Federais de Ensino Superior emitiu a seguinte nota:

A Andifes profundamente consternada, comunica o trágico falecimento do Prof. Dr.
Luiz Carlos Cancellier, Reitor da Universidade Federal de Santa Catarina, ocorrido na
manhã desta segunda-feira. O sentimento de pesar compartilhado por todos/as os/as
reitores/as das universidades públicas federais, neste momento, é acompanhado de
absoluta indignação e inconformismo com o modo como foi tratado por autoridades
públicas o Reitor Cancellier, ante um processo de apuração de atos administrativos, ainda
em andamento e sem juízo formado. É inaceitável que pessoas de bem, investidas de
responsabilidades públicas de enorme repercussão social tenham a sua honra destroçada
em razão da atuação desmedida do aparato estatal. É inadmissível que o país continue
tolerando práticas de um Estado policial, em que os direitos mais fundamentais dos
cidadãos são postos de lado em nome de um moralismo espetacular. É igualmente
intolerável a campanha que os adversários das universidades públicas brasileiras hoje
travam, desqualificando suas realizações e seus gestores, como justificativa para suprimir
o direito dos cidadãos à educação pública e gratuita. Infelizmente, todos esses fatos se
juntam na tragédia que hoje temos que enfrentar com a perda de um dirigente que por
muitos anos serviu à causa pública. A ANDIFES manifesta a sua solidariedade aos
familiares e amigos do Reitor Cancellier e continuará lutando pelo respeito devido às
universidades públicas federais, patrimônio de toda a sociedade brasileira
(ANDIFES,2017).

\section{$O$ caso $U F M G$}

No dia 06 de dezembro de 2017 o Reitor e a Vice-Reitora da UFMG (Universidade Federal de Minas Gerais) Jaime Arturo Ramirez e Sandra Regina Goulart de Almeida, foram conduzidos coercitivamente pela Polícia Federal, sob a acusação de desvio de 4 milhões de reais da construção do Memorial da Anistia Política do Brasil financiado pelo Ministério da Justiça. Segundo Rosário (2016, SN) "policiais invadiram sua casa no momento em que ele saía do banho, enrolado numa toalha. O reitor pediu tempo para trocar de roupa, e um dos policiais lhe respondeu, ríspido: o senhor não tem mais direito à privacidade".

Em nota a ANDIFES (Associação dos dirigentes das instituições federais) destacou que:

é notória a ilegalidade da medida, que repete práticas de um Estado policial, como se passou com a prisão injustificada do Reitor Luiz Carlos Cancellier de Olivo, da Universidade Federal de Santa Catarina, há pouco mais de dois meses. Apenas o desprezo pela lei e a intenção política de calar as Universidades, lócus do pensamento crítico e da promoção da cidadania, podem justificar a opção de conduzir coercitivamente, no lugar de simplesmente intimar para prestar as informações eventualmente necessárias. Ações espetaculosas, motivadas ideologicamente e nomeadas com ironia para demonstrar o desprezo por valores humanistas, não ajudam a combater a real corrupção do País, nem 
contribuem para a edificação de uma sociedade democrática. É sintomático que este caso grotesco de abuso de poder tenha como pretexto averiguar irregularidades na execução do projeto Memorial da Anistia do Brasil, que tem, como uma de suas finalidades, justamente preservar, em benefício das gerações atuais e futuras, a lembrança de um período lamentável da nossa história. Na ditadura, é bom lembrar, o arbítrio e o abuso de autoridade eram, também, práticas correntes e justificadas com argumentos estapafúrdios (ANDIFES, 2017).

Em um artigo publicado no Boletim da UFMG o reitor Ricardo Marcelo da UFPR (Universidade Federal do Paraná) também se manifestou no caso das prisões dos reitores da UFMG e lembrou também de duas outras operações ocorridas na UFRGS (Universidade Federal do Rio Grande do Sul) e na UFPR (Universidade Federal do Paraná) nas quais foram mobilizados dezenas de agentes federais e que foram foco de grande atenção da mídia televisiva. Sobretudo destacou que

O momento é de fato grave: enquanto deputados ou senadores filmados em flagrante delito por graves desvios são soltos pelos seus pares, reitores têm sua liberdade cassada. A sociedade deve, com muita premência, pensar que tipo de mundo pretende construir quando instituições como as universidades públicas (responsáveis por cerca de $90 \%$ da ciência e tecnologia do Brasil) são demonizadas, expostas, desrespeitadas e quando seus dirigentes são imolados publicamente (FONSECA, 2017).

\section{A análise da História - totalidade e violência}

Para analisar as inúmeras ações governamentais que ocorreram durante o breve e intenso governo de Michel Temer adotamos duas categorias e/ou dimensões do materialismo dialético, a totalidade e a violência. Adotar a dialética marxista nos ajuda a entender a essência do fenômeno a partir da realidade social apresentada, considerando o tempo histórico construído pelos sujeitos. Ora, a totalidade e a violência nos parece ser duas dimensões adequadas para se analisar o fenômeno em questão "a política científica brasileira entre 2016 e 2017 ”.

A totalidade nessa perspectiva é compreendida como a unidade entre realidade e a teoria sobre a realidade (KOSÍK, 1976) pois essa dimensão possibilita a compreensão das relações políticas, econômicas e sociais da ciência no âmbito da dialética entre desenvolvimento - subdesenvolvimento. A violência por outro lado reflete os meios pelos quais a classe dominante nacional e internacional aplicam suas políticas contra as instituições nacionais que atendem a classe trabalhadora, particularmente no Brasil, os sistemas públicos de saúde e educação. Segundo Vázquez (2011) o Estado é o meio e o agente da violência em sociedades divididas em classes antagônicas. A classe que está no poder utiliza o Estado para assegurar a dominação ou o consentimento dos interesses da classe por outros caminhos não coercitivos, aquela que está prestes a converter-se em ato. A violência em ato serve para materializar a dominação de uma classe sobre a outra.

\section{A totalidade - a ciência e a tecnologia no Brasil sob a imposição da dependência e do subdesenvolvimento}

Sendo a dialética da totalidade concreta uma teoria da realidade e do conhecimento que dela se tem como realidade (KOSÍK, 1976) considera-se que as diversas ações do governo Temer para aleijar a 
ciência nacional no período destacado baseia-se numa política nacional e internacional para produzir subdesenvolvimento e dependência aos países da periferia do capitalismo, argumentos já apresentados por dois intelectuais brasileiros, Florestan Fernandes e Celso Furtado que nos ajudam a explicar a sabotagem da ciência brasileira.

No caso da ciência, desde a década de 60 o físico brasileiro José Leite Lopes tem denunciado o descaso do governo brasileiro com as instituições científicas e a subalternidade do Brasil em termos de ciência e tecnologia comparado a países como os Estados Unidos, a Alemanha, a França e a Inglaterra. Subalternidade devida não a incapacidade dos cientistas brasileiros, mas em razão de uma política interna ${ }^{3}$ quase que contínua de desinvestimento em ciência, combinada com uma política externa de sabotagem e espoliação realizada pelos países ricos que atualmente compõe o G5, G7, G20 e etc. Afirmação que encontra fundamento na análise do sociólogo Florestan Fernandes quando afirma que,

[...] os países latino-americanos enfrentam duas realidades ásperas: 1) estruturas econômicas, socioculturais e políticas internas que podem absorver as transformações do capitalismo, mas que inibem a integração nacional e o desenvolvimento autônomo; 2) dominação externa que estimula a modernização e o crescimento, nos estágios mais avançados do capitalismo, mas que impede a revolução nacional e uma autonomia real. Os dois aspectos são faces opostas da mesma moeda (FERNANDES, 1975, p. 26).

O subdesenvolvimento econômico, como resultado da política de exploração dos países ricos sobre os países latinos americanos, asiáticos, africanos e árabes, não só envolve a perpetuação de estruturas econômicas mais ou menos arcaicas, mas também promove a modernização limitada ou segmentada em todos os níveis da organização da economia, da sociedade e da cultura (FERNANDES, 1975) desses povos. Ora, enquanto economias periféricas ou nações de economia dependente como o Brasil compram produtos e tecnologias de toda ordem dos países ricos essas forças econômicas internacionais têm como recursos do seu poder:

a) o controle da tecnologia (e da Ciência), b) o controle do acesso às fontes de recursos não-renováveis, c) o controle das finanças, d) o controle dos mercados e o e) controle do acesso à mão-de-obra barata. Esses recursos reunidos e/ou combinados em doses diversas originam posições de força, que ocupam os Estados ou os grandes grupos econômicos na luta pela apropriação do excedente gerado pela economia internacional (FURTADO, 1978, p.115).

Em outros termos, tais nações tem um controle global sobre os modos de produção e o comércio de bens e produtos que vão desde sementes, medicamentos e tecnologia digital e minérios, à corporações financeiras e bancárias que influem na política econômica dos países periféricos, o que mais uma vez impõem o subdesenvolvimento a essas nações (FURTADO, 2018). De posse desses recursos os países ricos por meio de sanções econômicas, práticas protecionistas, golpes de Estado e ações armadas, mantém o monopólio da produção científica e tecnológica industrial mundial, enquanto os países de economia dependente como o Brasil e de toda a América Latina devem ser fontes de commodities. Logo,

[...] a recusa, por parte das grandes empresas industriais estrangeiras, de abrirem laboratórios de pesquisa nos países de terceiro mundo é uma evidencia a mais contra qualquer política de ajuda e desenvolvimento desses países, com base na operação de tais companhias privadas (LOPES, 1978, p.32). 
Um exemplo disso são as indústrias farmacêuticas ${ }^{4}$, automobilísticas, de metalurgia e siderurgia. Tais corporações patenteiam espécies de plantas, compram ou extraem minérios do solo brasileiro a um preço irrisório para produzir medicamentos e tecnologias a preços elevados. Para manter essa lógica faz-se necessário desmontar a ciência nacional para que esta não produza tecnologias que concorram com as mercadorias estrangeiras tais como vacinas e medicamentos.

\section{A violência - o Estado contra os cientistas brasileiros}

Violenta foi a conquista, violenta foi a relação para com o indio, violenta a relação para com o negro, violenta para com o trabalhador organizado, violenta para com todos os pobres até os dias atuais (BOFF, 2000, p.41).

A violência contra universidades, estudantes e professores não é algo incomum no Brasil, o regime ditatorial militar instaurado a partir de 1964 deu início a uma política de repressão aos intelectuais e artistas nacionais, período em que dezenas de pesquisadores brasileiros foram expulsos do país. Dentre estes podemos citar, os físicos Jaime Tiyomo, José Leite Lopes, Elisa Frota Pessoa e Mário Schenberg, este último chegou a ficar preso por 60 dias. A esta lista podemos acrescentar ainda os sociólogos Florestan Fernandes e Celso Furtado, o geógrafo Milton Santos, o médico Josué de Castro, o educador Paulo Freire, o antropólogo Darcy Ribeiro e também o médico e filósofo Álvaro Vieira Pinto. Nesse período na UnB 200 professores foram forçados a se demitirem após sucessivas investidas intimidadoras, ameaças e perseguições, Roberto Salmeron retratou esse episódio em seu Livro "Universidade Interrompida Brasília 1964-1965”. Com relação a esse momento histórico o físico Herch Moysés Nussenzveig (1968) salientou que durante o governo do general Castelo Branco,

A falta de respeito pelo trabalho científico se manifestou através de um elemento novo: as perseguições políticas. Desencadeou-se uma avalanche de perseguições em várias universidades e institutos, onde se instalaram comissões militares submetendo os professores universitários a um tratamento degradante. Cientistas na maioria inteiramente alheios à política foram vítimas de interrogatórios e prisão. Vários foram demitidos dos seus lugares. "Colegas", a quem a presença de um pesquisador sempre fora incomoda, se apressaram em denunciá-lo como subversivo. Em diversos institutos o clima de suspeita e delação, acompanhado da intervenção dos elementos anticientíficos, com apoio governamental, tornou impossível a continuação de atividades de pesquisa. Em consequência inúmeros cientistas deixaram o país (NUSSENZVEIG, 1968, p.119).

Tais memórias ligadas aos fatos mais recentes retratados nesse trabalho nos leva a concordar com Rosa de Luxemburgo quando ela afirma que "a acumulação primitiva é um traço permanente da expansão imperialista desde o século XVI aos dias de hoje” (LÖWY, 2015 p. 93), na qual a violência é a consequência direta do choque que se estabelece entre o capitalismo e as formações que, na economia natural, interpõem barreiras a esta acumulação. Desse modo a tentativa de destruição da universidade pública brasileira está relacionada a agenda capitalista de apropriação e dominação dessa propriedade da cultura nacional que tem uma tradição de produção científica voltada as demandas sociais nacionais. Na concepção de Pereira (2019, p.3),

[...] hoje, quando o capital monopolista lá de trás, se expande e concentra exacerbadamente e o capital bancário fictício detém a hegemonia, vemos surgir políticas 
que flertam com o fascismo, mesmo em formações sociais com regimes democráticos burgueses, são práticas persecutórios àqueles que tem posições divergentes de quem está no poder, asfixia da crítica, a máquina de mídias de autopropaganda e de fakee news, de desqualificação de quem se opõe, um ranço de fundamentalismo ignorante, anti-ciência, anti-filosofia, anti-arte.

Tal condição explica as prisões expedidas por juízes federais de reitores e professores nas universidades federais brasileiras cumpridas pela polícia federal sem qualquer respeito a pessoa e aos direitos constitucionais dos trabalhadores em educação. Marx e Engels (2001), nos ensinam que a classe dominante, por meio dos elementos constituintes da superestrutura, neste caso específico o Estado e o Poder Judiciário, usa de todos os artifícios para manutenção de seu poder, por meio da produção de ideias e representações que formam um corpo ideológico de sua sustentação e de sua legitimação. Nesse âmbito a violência esta na raiz dos regimes capitalistas sejam eles ditatoriais ou democráticos e no caso particular do Brasil, a nova onda neoliberal traz o autoritarismo como uma forma de imposição de políticas que tem o objetivo de ceifar os direitos dos trabalhadores da educação, e também de outras categorias que por esta razão são reprimidas com a intenção de esvaziar o espaço de diálogo ou de questionamentos das ações governamentais, que gera uma esfera de violência contra os sujeitos que recusam ser furtados dos direitos historicamente construídos pela classe trabalhadora. Nesse sistema as classes oprimidas sofrem uma dupla violência, a primeira vinculada a precarização das suas condições de trabalho e a segunda na forma de repressão policial.

\section{Considerações finais}

Ao observar todas as ações ocorridas durante o governo de Michel Temer e descritas nesse trabalho, pode-se afirmar que agenda política brasileira no período analisado se concentrou entre outras práticas em desmontar, destruir, sabotar a produção científica brasileira, sobretudo utilizando-se de todo o arsenal ideológico, sensacionalista e principalmente político-jurídico para desqualificar, intervir e prender dirigentes das universidades públicas federais como parte de uma agenda capitalista em direção a sua completa extinção. O flerte com o fascismo o qual se referiu a pesquisadora Maria de Fátima Rodrigues Pereira (2019), com Bolsonaro parece ter se tornado uma união estável entre o Estado e as elites brasileiras e estrangeiras, que mantém e amplia a sabotagem que acomete a ciência, a cultura e toda a classe trabalhadora brasileira. Diante desse quadro só resta uma saída para os/as cientistas e pesquisadores brasileiros, saírem dos laboratórios para se unirem a massa de trabalhadores que hoje mal conseguem comer com o salário que lhes são pagos, do contrário assistirão a supressão da universidade pública brasileira tal qual ocorreu com os direitos trabalhistas e previdenciários.

\section{Referências:}

AUSTIN, Steve. Fim da exclusividade da Petrobras no pré-sal e a farra das multinacionais. 17 out. 2017. CNQ. Disponível em:

http://cnq.org.br/artigos/fim-da-exclusividade-da-petrobras-no-pre-sal-e-a-farra-das-multinacionais05e2/. Acesso em: 09 Nov. 2017.

BOFF, Leonardo. A voz do arco-iris. Brasília: Letraviva, 2000. 
CANCELLIER, Luiz Carlos. Reitor Exilado. Jornal O Globo. 28 set. 2017. Disponível em: https://oglobo.globo.com/opiniao/reitor-exilado-21879420. Acesso em: 05 nov. 2017.

CARUSO, F. Reflexões sobre Ciência, Tecnologia e o Papel da Universidade em um país em desenvolvimento. Ciência e Sociedade, n.1, p.1-6. 1991.

FERNANDES, Florestan. Capitalismo dependente e classes sociais na América Latina. Rio de Janeiro: Zahar editores, 1975.

FONSECA, Ricardo. Reitor da UFPR relembra um 'ano de ataques' às universidades brasileiras. UFMG. 7 dez. 2017. Disponível em: https://ufmg.br/comunicacao/noticias/ricardo-fonseca-reitor-da-ufpr. Acesso em: 20 Jan. 2018.

FURTADO, Celso. Criatividade e Dependência na Civilização Ocidental. São Paulo: Paz e Terra, 1978.

FURTADO, Celso. A superação do subdesenvolvimento. Economia e Sociedade, [S.1.], v. 3, n. 1, p.37-42, out. 2016. Disponível em: <https://periodicos.sbu.unicamp.br/ojs/index.php/ecos/article/view/8643216>. Acesso em: 08 Agost. 2018.

LOPES, José Leite. Ciência e Libertação. 2.ed. Rio de Janeiro: Paz e Terra; 1978.

LÖWY, Michael. Imperialismo ocidental versus comunismo primitivo. In. Rosa Luxemburgo on o preço da liberdade. Jörn Schütrumpf (org). Tradução: Isabel Loureiro, Karin Glass, Kristina Michahelles e Monika Ottermann. São Paulo: Fundação Rosa Luxemburgo, 2015.

KOSÍK, Karel. Dialética do Concreto. Rio de Janeiro: Paz e Terra, 1976.

MARX, Karl; ENGELS, Friedrich. A ideologia alemã. São Paulo: Martins Fontes, 2001.

MORAES, José Mauro de. Petróleo em águas profundas: uma história tecnológica da Petrobrás na exploração e produção offshore. Brasília: Ipea; Rio de Janeiro: Petrobrás, 2013.

NOTA DA SBF. Manifestação do Conselho da SBF. 08 de dez. 2016. SBF. Disponível em:

http:/ / www.sbfisica.org.br/v1/index.php?option=com content\&view=article\&id=833:2016-12-08-1117-42\&catid=152: acontece-na-sbf\&Itemid=270. Acesso em: 17 Fev. 2017.

NOTA DA SBPC. Entidades científicas e acadêmicas repudiam novos cortes orçamentários em ciência, tecnologia, educação e saúde. SBPC. 04 Jun. 2018. Disponível em:

http://portal.sbpcnet.org.br/noticias/entidades-cientificas-e-academ. Acesso em: 09 Maio 2018.

NOTA DE PESAR. Andifes. 02 out. 2017. Disponível em: http://www.andifes.org.br/nota-de-pesar/. Acesso em: 05 fev. 2018.

NOTA DOS EDITORES. A Uerj e o Futuro do Rio de Janeiro. Espaço e Economia: Revista brasileira de geografia econômica, Ano V, n. 9. 2017.

NOTA PÚBLICA. Andifes denuncia a "ilegalidade da medida". Andifes. 6 dez. 2017. Disponível em: https://ufmg.br/comunicacao/noticias/andifes-critica-ilegalidade Acesso em: 18 Jan 2018.

NOTA PÚBLICA. Universidade é lugar de conhecimento e liberdade. 29 Julho 2018. Andifes. Disponível em: http://www.andifes.org.br/universidade-e-lugar-de-conhecimento-e-liberdade/. Acesso em: 08 Agosto 2018.

NUSSENZVEIG, Herch Moysés. Êxodo de Cientistas: as suas causas e possíveis soluções. Revista Paž e Terra - Homem, Ciência e Tecnologia. Ano II, n. 8, p. 109-124. 1968.

PEREIRA, Maria de Fátima Rodrigues. O fascismo, ontem e hoje: denúncias e resistências. Revista Germinal: Marxismo e Educação em Debate, v. 11, n. 2, p 1-6., abr. 2019.

PETHERICK, Anna. Careers: Austerity bites deeply. Nature. v. 548, p. 249-251, 10 de Ago. 2017. Disponível em: https://www.nature.com/nature/journal/v548/n7666/full/nj7666-249a.html .

RIBEIRO, Darcy. O povo brasileiro: a formação e o sentido do Brasil. São Paulo: Companhia das letras, 2006.

RODRIGUES, José Honório. Conciliação e Reforma no Brasil: Um desafio bistórico-politico. Rio de Janeiro: Editora Civilização Brasileira S. A., 1965. 
ROSÁRIO, M. do. Reitor da UFMG preso foi humilhado por policiais. O caferzinho. 06 dez. 2016. Disponível em: https://www.ocafezinho.com/2017/12/06/reitor-da-ufmg-preso-foi-humilhado-porpoliciais/. Acesso em: 20 ago. 2017.

SALMERON, Roberto. A Universidade Interrompida Brasília 1964-1965. Brasília: Editora Universidade de Brasília, 1999.

TORRES, Aline. O suicídio do reitor para quem prisão foi ultraje e sentença de morte. 04. Out. 2017. El País. Disponível em: https://brasil.elpais.com/brasil/2017/10/04/politica/1507084756 989166.html . Acesso em: 20 Jan. 2018.

VASCO, Paulo Sérgio; GOMIDE, Silvia. Senado aprova criação do fundo social do Pré-sal regime de partilha e distribuição dos royalties a todos os estados. 10 Jun. 2010. Agência Senado, Brasília. Disponível em: https://www12.senado.leg.br/noticias/materias/2010/06/10/senado-aprova-criacao-do-fundosocial-do-pre-sal-regime-de-partilha-e-distribuicao-dos-royalties-a-todos-os-estados . Acesso em: 25 abr. 2017.

VÁZQUEZ, Adolfo Sánchez. Filosofia da Práxis. Trad. Maria Encarnación Moya São Paulo: expressão popular, 2011.

\section{Notas:}

${ }^{1}$ Docente do curso de Licenciatura em Educação do Campo - Ciências da Natureza. Doutorado em Ensino de Ciências e Educação Matemática pela Universidade Estadual de Londrina com sanduíche na Universidade de Massachussets - Amherst- USA. Licenciado em Física. http://orcid.org/0000-0002-0397-4754 Email: robertobarbosa@ufpr.br

2 Disponível em: https://www25.senado.leg.br/web/atividade/materias/-/materia/127337. Acesso em:

3 A liderança nacional, em suas sucessivas gerações, foi de modo geral antirreformista, elitista, corrupta e conservadora. Sempre atuou para deixar o país no atraso, rouba o povo para manter os seus privilégios e recorrem com violência quando esses se rebelam (RODRIGUES, 1965).

${ }^{4}$ Recentemente, em outro episódio de auto-sabotagem nacional, o governo Temer liberou a patente do medicamento sofosbuvir a farmacêutica americana Gelead que cura em $95 \%$ os casos de hepatite C, decisão que impede a Fiocruz-farmanguinhos de produzir o sofosbuvir genérico o que geraria a economia de 1 Bilhão de reais ao Ministério da Saúde. 